\title{
In Vivo Butyrylcholinesterase Activity Is Not Increased in Alzheimer's Disease Synapses
}

\author{
David E. Kuhl, MD, ${ }^{1}$ Robert A. Koeppe, PhD,${ }^{1}$ Scott E. Snyder, PhD,${ }^{1}$ Satoshi Minoshima, MD, PhD, ${ }^{1,2}$ \\ Kirk A. Frey, MD, PhD, ${ }^{1,3}$ and Michael R. Kilbourn, $\mathrm{PhD}^{1}$
}

\begin{abstract}
Objective: We tested the premise that cholinesterase inhibitor therapy should target butyrylcholinesterase (BuChE) in Alzheimer's disease (AD), not acetylcholinesterase (AChE) alone, because both enzymes hydrolyze acetylcholine, and $\mathrm{BuChE}$ is increased in $\mathrm{AD}$ cerebral cortex. Methods: To examine this issue in vivo, we quantified human cerebral cortical BuChE activity using tracer kinetic estimates $\left(k_{3}\right)$ of $1-\left[{ }^{11} \mathrm{C}\right]$ methyl-4-piperidinyl $n$-butyrate $\left(\left[{ }^{11} \mathrm{C}\right] \mathrm{BMP}\right)$ hydrolysis determined by positron emission tomography. Validation of the putative positron emission tomography method included regional distribution, positive correlation with age, and attenuation by the nonselective cholinesterase inhibitor physostigmine, but no attenuation by the AChE-selective inhibitor donepezil. Positron emission tomography scans in $\mathrm{AD}$ patients $(n=15)$ and control subjects $(n=12)$ measured both BuChE (using $\left.\left[{ }^{11} \mathrm{C}\right] \mathrm{BMP}\right)$ and AChE activity (using $\mathrm{N}-\left[{ }^{11} \mathrm{C}\right]$ methylpiperidin-4-yl propionate, an established method). Results: As expected, AChE activity in AD cerebral cortex was decreased to $75 \pm 13 \%$ of normal $(p=0.00001)$. Contrary to prediction, accompanying BuChE activity also was decreased to $82 \pm 14 \%$ of normal $(p=0.001)$. Interpretation: Failure to observe increased $\left[{ }^{11} \mathrm{C}\right] \mathrm{BMP}$ hydrolysis in vivo makes it less likely that incremental $\mathrm{BuChE}$ contributes importantly to acetylcholine hydrolysis in $\mathrm{AD}$. The findings do not support the premise that inhibitor therapy should target $\mathrm{BuChE}$ so as to prevent increased levels of BuChE from hydrolyzing acetylcholine in $\mathrm{AD}$ cerebral cortex.
\end{abstract}

Ann Neurol 2006;59:13-20

There are two principal cholinesterases in the human brain, acetylcholinesterase (AChE; EC 3.1.1.7) and butyrylcholinesterase (BuChE; EC 3.1.1.8). AChE is membrane bound predominantly on presynaptic cholinergic neurons, but is also on postsynaptic cholinoceptive neurons. ${ }^{1}$ BuChE has a neuroglial distribution. ${ }^{2,3}$ The physiological role of $\mathrm{AChE}$ is to terminate the synaptic action of acetylcholine (ACh) through catalytic hydrolysis. ACh is hydrolyzed by both $\mathrm{AChE}$ and $\mathrm{BuChE}$, but $\mathrm{AChE}$ catalyzes the hydrolysis of $\mathrm{ACh}$ much more efficiently than BuChE. ${ }^{4}$ The physiological role of BuChE is poorly understood, particularly in the central nervous system. Recent attention has focused on this enigmatic enzyme and its possible relevance in the treatment of Alzheimer's disease (AD).$^{5-11}$

Cholinesterase inhibitors have shown greater efficacy than placebo in clinical trials and are widely prescribed as symptomatic treatment to improve cognition and behavior in $\mathrm{AD}$ patients with mild or moderate dementia. The basis is the presynaptic cholinergic deficit that is found consistently in $\mathrm{AD}$ cerebral cortex. ${ }^{12-14}$ The rationale is to increase the availability of $\mathrm{ACh}$ within cholinergic synapses by reducing its hydrolysis. Opinion differs on the issue whether these drugs should be selective inhibitors of AChE alone (eg, donepezil) or nonselective inhibitors of both AChE and $\mathrm{BuChE}$ (eg, rivastigmine). In the absence of cholinesterase inhibitors that are selective for $\mathrm{BuChE}$, the potential efficacy of BuChE inhibition has been difficult to establish from clinical trials. ${ }^{7,15}$ Proponents of AChE-selective inhibitors claim less peripheral adverse effects, ${ }^{16,17}$ whereas some reject these results. ${ }^{18}$ Proponents of nonselective inhibitors argue that if only $\mathrm{AChE}$ is inhibited, ACh will continue to be hydrolyzed by uninhibited $\mathrm{BuChE}$ that is known to be increased in $\mathrm{AD}$ cerebral cortex. ${ }^{5-11}$ However, the magnitude and clinical significance of this process has not yet been established in vivo. ${ }^{16}$

To explore this issue directly, we tested the hypothesis that in vivo measures in cerebral cortex of $A D$ patients with mild or moderate dementia would demonstrate the same discordant relation between AChE (decrease) and BuChE activity (increase) as has been documented from in vitro studies of postmortem $\mathrm{AD}$
From the ${ }^{1}$ Division of Nuclear Medicine, Department of Radiology, University of Michigan, Ann Arbor, MI; ${ }^{2}$ Division of Nuclear Medicine, Department of Radiology, University of Washington, Seattle, WA; and ${ }^{3}$ Department of Neurology, University of Michigan, Ann Arbor, MI.

Received May 26, 2005, and in revised form Aug 26. Accepted for publication Aug 26, 2005.
Published online Nov 8, 2005 in Wiley InterScience (www.interscience.wiley.com). DOI: 10.1002/ana.20672

Address correspondence to Dr Kuhl, Division of Nuclear Medicine, Department of Radiology, University of Michigan Medical Center, 1500 East Medical Center Drive, Ann Arbor, MI 48109-0028. E-mail: dkuhl@umich.edu 
brain. ${ }^{2,9,19-23}$ First, we identified $1-\left[{ }^{11} \mathrm{C}\right]$ methyl-4piperidinyl $\mathrm{n}$-butyrate $\left(\left[{ }^{11} \mathrm{C}\right] \mathrm{BMP}\right)$ as a ligand superior for the in vivo measurement of cerebral BuChE activity based on specificity determined by in vitro assay and pharmacokinetics determined by in vivo measurements in primate brain. ${ }^{24}$ Next, we validated the quantitative measure of in vivo human cerebral cortical BuChE activity using tracer kinetic estimates of $\left[{ }^{11} \mathrm{C}\right] \mathrm{BMP}$ hydrolysis determined by positron emission tomography (PET). Finally, we performed PET scans in AD patients and in healthy control subjects to measure both $\mathrm{BuChE}$ activity, using $\left[{ }^{11} \mathrm{C}\right] \mathrm{BMP}$, and accompanying $\mathrm{AChE}$ activity, using $N-\left[{ }^{11} \mathrm{C}\right]$ methylpiperidin-4-yl propionate $\left(\left[{ }^{11} \mathrm{C}\right] \mathrm{PMP}\right)$, a previously established method. ${ }^{25-30} \mathrm{Re}-$ cently, Roivainen and colleagues ${ }^{31}$ reported using $\left[{ }^{11} \mathrm{C}\right] \mathrm{BMP}$ with PET to map BuChE activity in human brain, but no comparisons were made of $\mathrm{AD}$ patients versus control subjects.

\section{Subjects and Methods}

\section{Subjects}

A young control group consisted of 13 healthy subjects across an age range from 20 to 47 years (mean age, $30 \pm 9$ years; 4 female and 9 male subjects) and an elderly control group consisted of 12 healthy subjects across an age range from 55 to 68 years (mean age, $62 \pm 7$ years; 8 female and 4 male subjects). Healthy subjects had no history of significant general medical, neurological, or psychiatric illness, head injury with loss of consciousness, or drug or alcohol dependence, and they were not taking any medications with central nervous system actions. An AD group consisted of 15 subjects across an age range from 59 to 82 years (mean age, $73 \pm 8$ years; 9 female and 6 male subjects). AD subjects were not taking any medications with actions known to affect the central cholinergic system. All were required to be mildly or moderately demented and to have a clinical diagnosis of probable AD. ${ }^{32}$ Mean Clinical Dementia Rating ${ }^{33}$ was $1.1 \pm 0.4$. Mean Mini-Mental State Examination ${ }^{34}$ score was $19 \pm 4$. This study was approved by an institutional review board. Written, informed consent was obtained from all subjects or their caregivers.

\section{Radiotracers}

Details of preparation of $\left[{ }^{11} \mathrm{C}\right] \mathrm{BMP}^{24}$ and $\left[{ }^{11} \mathrm{C}\right] \mathrm{PMP}^{27}$ have been reported. In vitro assays have characterized piperidinyl esters as substrates for AChE and BuChE. ${ }^{24-26,35}\left[{ }^{11} \mathrm{C}\right] \mathrm{PMP}$ is a selective substrate for $\mathrm{AChE}$, with a selectivity in ex vivo cholinesterase assays of $97 \%$ for AChE. ${ }^{25}\left[{ }^{11} \mathrm{C}\right] \mathrm{BMP}$ is not a substrate for AChE.

\section{Scan Protocols and Analysis}

Data were acquired using a PET scanner (Siemens ECAT EXACT-47; CTI, Knoxville, TN) in three-dimensional mode. Final image resolution was $10.0 \mathrm{~mm}$ (full-width at half-maximum) in-plane and axially. Each radiotracer was injected intravenously as a $444 \mathrm{MBq}(12 \mathrm{mCi})$ dose. We limited a $\left[{ }^{11} \mathrm{C}\right] \mathrm{BMP}$ dose arbitrarily to a total injected mass less than $25 \mu \mathrm{m} / 70 \mathrm{~kg}$ person. When used sequentially on the same day, $\left[{ }^{11} \mathrm{C}\right] \mathrm{BMP}$ was injected first, and then $\left[{ }^{11} \mathrm{C}\right] \mathrm{PMP}$ was injected after an interval of 2 hours. Tracer input functions were determined from serial blood samples withdrawn through a radial artery catheter. The fraction of unmetabolized tracer in plasma samples was determined. Data acquisition and analysis were performed as reported previously. ${ }^{30}$ A three-compartment model ${ }^{28,29}$ was used to yield pixel-bypixel estimates of the rate constant $k_{3}$, which represented the hydrolysis rate (activity) of either BuChE or AChE. Regional values of $\mathrm{k}_{3}$ were extracted using the three-dimensional stereotactic surface projection technique. ${ }^{36}$ Data were not corrected for partial-volume effects. Any effect of cerebral cortical atrophy should account for less than an $8 \%$ reduction in the kinetically estimated values of $\left[{ }^{11} \mathrm{C}\right] \mathrm{BMPk}_{3}$ or $\left[{ }^{11} \mathrm{C}\right] \mathrm{PMPk}_{3} .{ }^{28}$ Statistical methods included two-sample $t$ tests assuming equal variances and different sample sizes for minimum detectable differences, two-tailed paired and unpaired $t$ tests of significance, and two-factor repeatedmeasures analysis of variance. Reproducibility was estimated for test-retest variability, that is, the absolute difference in measured activity between the test and the retest divided by the average of the two studies and expressed as a percentage.

\section{Inhibition Protocols}

Validation included measuring cerebral cortical responses of $\left[{ }^{11} \mathrm{C}\right] \mathrm{BMP} \mathrm{k}_{3}$ and $\left[{ }^{11} \mathrm{C}\right] \mathrm{PMP} \mathrm{k}_{3}$ after treatment with wellcharacterized drugs ${ }^{37,38}$ known to be selective (donepezil) and nonselective (physostigmine) cholinesterase inhibitors. Young control subjects were scanned with $\left[{ }^{11} \mathrm{C}\right] \mathrm{BMP}(\mathrm{n}=$ 4) or $\left[{ }^{11} \mathrm{C}\right] \mathrm{PMP}(\mathrm{n}=5)^{28}$ before and after a constant rate infusion of physostigmine salicylate (Antilirium TM; Forest Pharmaceuticals, St. Louis, MO) in a dose of $1.5 \mathrm{mg}$ in $100 \mathrm{ml}$ saline over a period of 60 minutes. ${ }^{28}$ Four AD patients (CDR1) were scanned with both $\left[{ }^{11} \mathrm{C}\right] \mathrm{BMP}$ and $\left[{ }^{11} \mathrm{C}\right] \mathrm{PMP}$ before and after treatment with donepezil hydrochloride (5mg/day; Aricept TM; Pfizer, New York, NY) for a 2- to 6-month period. After treatment, $\mathrm{k}_{3}$ data were expressed as percentage decrease from pretreatment values (inhibition).

\section{Alzheimer's Disease Protocol}

Both a $\left[{ }^{11} \mathrm{C}\right] \mathrm{BMP}$ and a $\left[{ }^{11} \mathrm{C}\right] \mathrm{PMP}$ PET scan were performed on each elderly control subject $(n=12)$ and $A D$ subject $(\mathrm{n}=15)$ to quantify in vivo BuChE activity and accompanying AChE activity in normal and $\mathrm{AD}$ cerebral cortex.

\section{Results

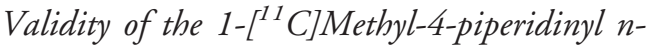 Butyrate Method}

REPRODUCIBILITY. In cerebral cortex of elderly control subjects, the coefficients of variation for intersubject $(\mathrm{n}=12)$ measurements of $\left[{ }^{11} \mathrm{C}\right] \mathrm{BMP} \quad \mathrm{k}_{3}$ and $\left[{ }^{11} \mathrm{C}\right] \mathrm{PMP} \mathrm{k}_{3}$ were 11 and $12 \%$, respectively. Intrasubject test-retest measures made at 2-month intervals using $\left[{ }^{11} \mathrm{C}\right] \mathrm{BMP}(\mathrm{n}=5)$ and $\left[{ }^{11} \mathrm{C}\right] \mathrm{PMP}(\mathrm{n}=6)$ differed by $7 \pm 5$ and $6 \pm 3 \%$, respectively. 
DISTRIBUTION. Our in vivo measures of $\left[{ }^{11} \mathrm{C}\right] \mathrm{BMP} \mathrm{k}_{3}$ and $\left[{ }^{11} \mathrm{C}\right]$ PMP $\mathrm{k}_{3}$ (Table) in healthy control cases agreed well with relative regional distributions of $\mathrm{BuChE}$ and AChE activity based on biochemical assay of postmortem human brain. ${ }^{39}$ BuChE activity ranged from low in cerebral cortex to 2.5 times higher in cerebellum (Fig 1), and AChE activity ranged from low in cerebral cortex to 21 times higher in caudate nucleus.

AGE AND SEX. Cerebral cortical $\left[{ }^{11} \mathrm{C}\right] \mathrm{BMP} \mathrm{k}_{3}$ increased with age, whereas $\left[{ }^{11} \mathrm{C}\right] \mathrm{PMP} \mathrm{k}_{3}$ did not, ${ }^{28} \mathrm{a}$ finding in agreement with biochemical assays of postmortem brain. ${ }^{19,23}\left[{ }^{11} \mathrm{C}\right] \mathrm{BMP} \mathrm{k}_{3}$ in total cerebral cortex averaged $25 \%$ higher in elderly (age, $62 \pm 7$ years; $\mathrm{n}=12$ ) than in young (age, $30 \pm 9$ years; $\mathrm{n}=13$ ) subjects. Between either the age groups or the sex groups, the minimum detectable difference was $14 \%$ (80\% power at $p<0.05)$. Using a two-factor analysis of variance (age and sex as factors), we noted a significant age effect $(p=0.009)$, with $\left[{ }^{11} \mathrm{C}\right] \mathrm{BMP} \mathrm{k}_{3}$ increasing with age. Neither sex effect $(p=0.15)$ nor age by sex interaction $(p=0.17)$ were significant. Relative to parietal cortex distribution, regional $\left[{ }^{11} \mathrm{C}\right] \mathrm{BMP}$ $\mathrm{k}_{3}$ cerebral cortical distributions (frontal, temporal, occipital, visual, posterior cingulate) did not differ significantly $(p>0.1)$ between young and elderly subjects.

RESPONSE TO INHIBITORS. As predicted, acute administration of the nonselective inhibitor physostigmine (1.5mg infusion) inhibited both $\mathrm{BuChE}$ and $\mathrm{AChE}$ significantly in normal cerebral cortex (Fig 2). BuChE inhibition measured with $\left[{ }^{11} \mathrm{C}\right] \mathrm{BMP}(\mathrm{n}=4)$ was
$49 \pm 6 \%(p=0.001)$, and AChE inhibition measured with $\left[{ }^{11} \mathrm{C}\right] \mathrm{PMP}(\mathrm{n}=5)$ was $52 \pm 9 \%(p=$ $0.0002){ }^{28}$ The inhibition levels of the two cholinesterases did not differ significantly $(p=0.6)$. As predicted, treatment with the selective AChE inhibitor donepezil $(5 \mathrm{mg} /$ day for $2-6$ months; $\mathrm{n}=4)$ inhibited only AChE in AD cerebral cortex (see Fig 2). BuChE inhibition measured with $\left[{ }^{11} \mathrm{C}\right] \mathrm{BMP}$ was $4 \pm 12 \%$ and was not significant $(p=0.5)$. Accompanying AChE inhibition measured with $\left[{ }^{11} \mathrm{C}\right] \mathrm{PMP}$ was $27 \pm$ $5 \%$ and was significant $(p=0.003)$.

\section{Alzheimer's Disease}

When $\left[{ }^{11} \mathrm{C}\right] \mathrm{BMP}$ and $\left[{ }^{11} \mathrm{C}\right] \mathrm{PMP}$ PET scans were compared (Fig 3) between elderly control subjects $(\mathrm{n}=12)$ and $\mathrm{AD}$ patients $(\mathrm{n}=15)$, in vivo $\mathrm{AChE}$ activity in overall $\mathrm{AD}$ cerebral cortex was found to be decreased to $75 \pm 13 \%$ of normal $(p=0.00001)$. Associated in vivo $\mathrm{BuChE}$ activity was not found increased, but instead was decreased to $82 \pm 14 \%$ of normal $(p=$ 0.001). The minimum detectable difference in cerebral cortex between elderly control subjects and $\mathrm{AD}$ patients was $13 \%$ with $\left[{ }^{11} \mathrm{C}\right] \mathrm{BMP} \quad \mathrm{k}_{3}$ and $12 \%$ with $\left[{ }^{11} \mathrm{C}\right]$ PMP $\mathrm{k}_{3}(80 \%$ power at $p<0.05)$. The difference between $\left[{ }^{11} \mathrm{C}\right] \mathrm{BMP} \mathrm{k}_{3}$ decrease (mean, $18 \%$ ) and $\left[{ }^{11} \mathrm{C}\right]$ PMP $\mathrm{k}_{3}$ decrease (mean, 25\%) was significant $(p=0.05)$. The difference between the ratio $\left[{ }^{11} \mathrm{C}\right] \mathrm{BMPk}_{3} /\left[{ }^{11} \mathrm{C}\right] \mathrm{PMPk}_{3}$ measured in normal $(0.94 \pm 0.13)$ and in $\mathrm{AD}$ cerebral cortex (1.04 \pm $0.17)$ was not significant $(p=0.13)$. As noted earlier, no compensatory increase in BuChE activity accompa-

Table. Distribution of Butyrylcholinesterase and Acetylcholinesterase Activities: In Vivo versus Postmortem Biochemical Assay

\begin{tabular}{|c|c|c|c|c|}
\hline \multirow[b]{2}{*}{ Regions } & \multicolumn{2}{|c|}{$\begin{array}{l}\text { Relative BuChE Activity } \\
\quad(\text { mean } \pm \text { SD) }\end{array}$} & \multicolumn{2}{|c|}{$\begin{array}{l}\text { Relative AChE Activity } \\
\quad(\text { mean } \pm S D)\end{array}$} \\
\hline & $\begin{array}{c}\text { In Vivo } \\
{\left[{ }^{11} \mathrm{C}\right] \mathrm{BMP} \mathrm{k} \mathrm{k}_{3}^{* a}}\end{array}$ & $\begin{array}{l}\text { Postmortem } \\
\text { Biochemical }\end{array}$ & $\begin{array}{c}\text { In Vivo } \\
{\left[{ }^{11} \mathrm{C}\right] \text { PMP k }{ }_{3}^{* a}}\end{array}$ & $\begin{array}{l}\text { Postmortem } \\
\text { Biochemical }\end{array}$ \\
\hline Cerebellum & $2.50 \pm 0.39$ & $2.90 \pm 0.04$ & $8.97 \pm 2.00$ & $12.0 \pm 2.2$ \\
\hline Putamen & $1.74 \pm 0.11$ & & $20.7 \pm 3.6$ & \\
\hline Caudate nucleus & $1.58 \pm 0.10$ & $1.97 \pm 0.23$ & $21.4 \pm 4.6$ & $54.7 \pm 6.7$ \\
\hline Thalamus & $1.28 \pm 0.12$ & & $2.60 \pm 0.31$ & \\
\hline Pons & $1.14 \pm 0.14$ & & $5.44 \pm 1.24$ & \\
\hline \multicolumn{5}{|l|}{ Cerebral cortex } \\
\hline Frontal cortex & $0.93 \pm 0.06$ & & $1.05 \pm 0.07$ & \\
\hline Temporal cortex & $0.91 \pm 0.04$ & $1.47 \pm 0.35$ & $1.06 \pm 0.08$ & $1.5 \pm 0.3$ \\
\hline Occipital cortex & $0.99 \pm 0.05$ & & $0.96 \pm 0.05$ & \\
\hline Visual cortex & $0.96 \pm 0.08$ & & $0.94 \pm 0.06$ & \\
\hline Posterior cingulate cortex & $0.99 \pm 0.07$ & & $1.10 \pm 0.08$ & \\
\hline Parietal cortex & $1.00 \pm 0.00$ & $1.00 \pm 0.25$ & $1.00 \pm 0.00$ & $1.0 \pm 0.1$ \\
\hline
\end{tabular}

Relative activity indices are relative to the corresponding parietal cortex measure. In vivo butyrylcholinesterase (BuChE) and acetylcholinesterase (AChE) activities were determined and were normalized to the parietal cortex measure in each elderly healthy control subject $(\mathrm{n}=12)$. Postmortem indices were calculated from the published data of Atack and colleagues. ${ }^{39}$ Activities in each elderly control brain $(\mathrm{n}=3-5)$ were normalized to the mean parietal cortex measure.

${ }^{a}$ The rate constant $\mathrm{k}_{3}^{*}$ represents cholinesterase activity, where the asterisk means relative to the parietal cortex.

$\mathrm{SD}=$ standard deviation; $\left[{ }^{11} \mathrm{C}\right] \mathrm{BMP}=1-\left[{ }^{11} \mathrm{C}\right]$ methyl-4-piperidinyl n-butyrate; $\left[{ }^{11} \mathrm{C}\right] \mathrm{PMP}=N-\left[{ }^{11} \mathrm{C}\right]$ methylpiperidin-4-yl propionate. 


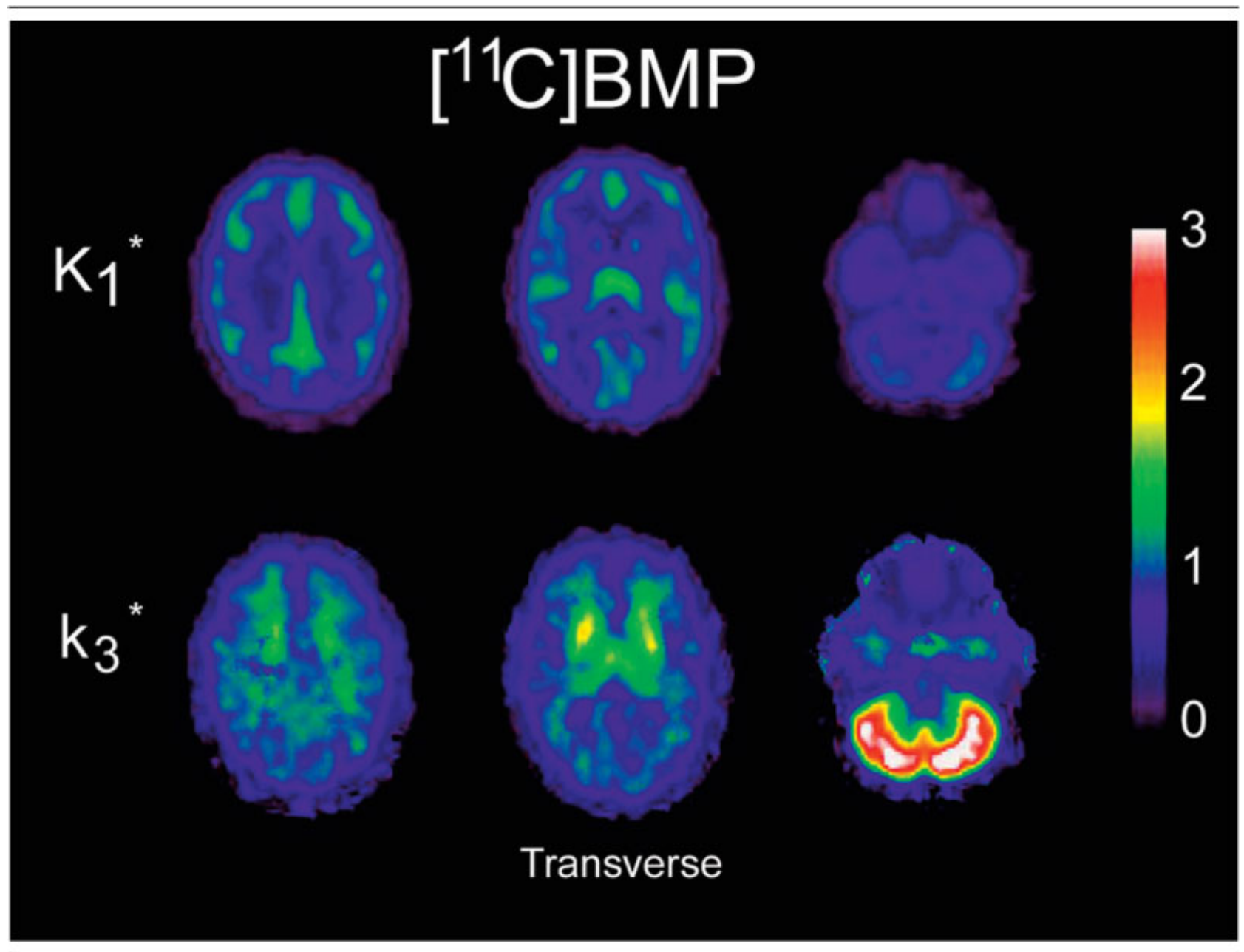

Fig 1. Parametric images of $1-\left[{ }^{11} C\right]$ methyl-4-piperidinyl n-butyrate $\left(\left[{ }^{11} C\right] B M P\right)$ kinetics within three brain levels of a healthy control subject, all normalized to mean values in parietal cortex. The rate constant $K_{3}^{*}$ represents delivery, and the rate constant $k_{3}^{*}$ represents butyrylcholinesterase activity, where the asterisk means relative to the parietal cortex. Compared with cerebral cortex, butyrylcholinesterase activity is higher in cerebellum, striatum, thalamus, and subcortical white matter, where it is localized in glial cells. $^{39}$

nied selective inhibition of AChE activity in AD cortex.

\section{Discussion}

In vivo $A D$ brain did not demonstrate the substantial increase in BuChE activity predicted from in vitro studies of postmortem AD brain., ${ }^{2,9,19-23}$ Because we found that the activities of both cholinesterases were decreased in $\mathrm{AD}$ cerebral cortex, there was no in vivo evidence of the high ratios of $\mathrm{BuChE} / \mathrm{AChE}$ that have been proposed as regional markers of $\mathrm{AD}$ by in vitro studies. ${ }^{2,6}$ In addition, BuChE activity did not increase in human brain after months of selective AChE inhibition, an observation that was consistent with the reported absence of compensatory increase in $\mathrm{BuChE}$ activity in AChE-devoid brains of knock-out mice. ${ }^{40}$

We interpreted our results to be evidence that the incremental buildup of $\mathrm{BuChE}$ that is identified in postmortem $\mathrm{AD}$ brain does not contribute substantially to neuropil-associated $\mathrm{BuChE}$ activity in the living $\mathrm{AD}$ brain. We considered and rejected some alternative explanations. First, were the in vitro reports incorrect? We consider this unlikely. In vitro evidence is convincing from studies performed in multiple laboratories and with differing approaches that $\mathrm{BuChE}$ is increased in postmortem $\mathrm{AD}$ cerebral cortex. The in vivo neurochemical role and consequence of this incremental $\mathrm{BuChE}$, however, has been speculative. An early study based on quantitative biochemical measures in autopsied brain found that total AChE was reduced 33\% in $\mathrm{AD}$ temporal cortex, but total $\mathrm{BuChE}$ was increased $40 \% .{ }^{19}$ Histochemistry demonstrates both AChE and $\mathrm{BuChE}$ are bound to pathological AD substructures. ${ }^{20}$ For example, BuChE emerges from neuroglia ${ }^{2}$ and accumulates in pathological plaques, neurofibrillary tangles, and vessels affected by congophilic angiopa- 


\section{REF \\ BuChE $\left[{ }^{11} \mathrm{C}\right] \mathrm{BMP} \mathrm{k}_{3}$ \\ AChE $\left[{ }^{11} \mathrm{C}\right] \mathrm{PMP} \mathrm{k}_{3}$}

\section{Physostigmine in normals}
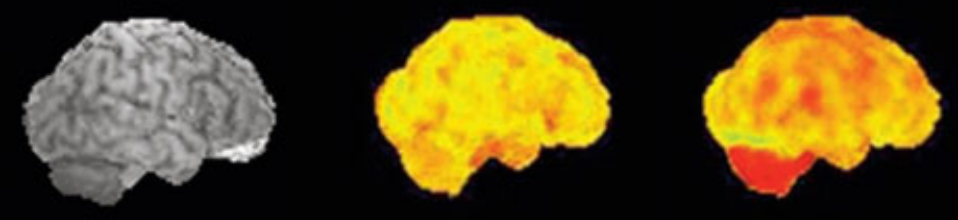

Donepezil in $A D$
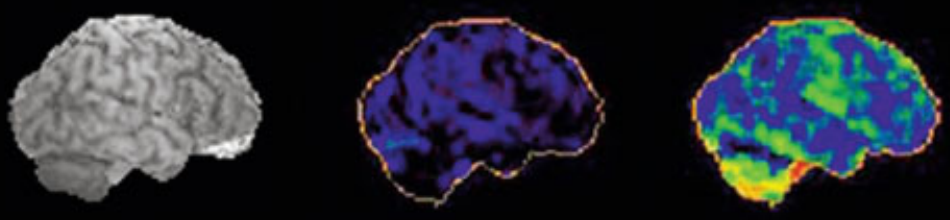

Right Lateral Hemisphere

Fig 2. Positron emission tomography (PET) scans using $1-\left[{ }^{11} C\right]$ methyl-4-piperidinyl n-butyrate $\left(\left[{ }^{11} C\right] B M P\right)$ and

$\mathrm{N}-\left[{ }^{11} C\right]$ methylpiperidin-4-yl propionate ( $\left.\left[{ }^{11} C\right] P M P\right)$ quantified correctly the in vivo inhibition of butyrylcholinesterase (BuChE) and acetylcholinesterase (AChE) activities expected after treatment with nonselective and selective cholinesterase inhibitor drugs. After acute administration of the nonselective inhibitor physostigmine, mean inhibition in cerebrocortical, striatal, thalamic, and pontocerebellar zones was 49, 50, 54, and 51\%, respectively, for BuChE $(n=4)$ and 52, 44, 61, and 64\%, respectively, for AChE ( $n=$ 5). After treatment for several months with the selective AChE inhibitor donepezil $(n=4)$, AChE inhibition in the same zones was 27, 31, 36, and 46\%, respectively, but BuChE was not inhibited in any zone. Image summations are right-left averages of percentage decrease from pretreatment values (percentage inhibition) plotted as three-dimensional stereotactic surface projections (reference anatomic map [REF]). Red color represents greater inhibition of BuChE or AChE by physostigmine or donepezil. AD = Alzheimer's disease.

thy. $^{2,20,22,23}$ This accumulation, especially that enzyme bound to mature compact neuritic plaques, ${ }^{41}$ is considered to account for the incremental BuChE observed in $\mathrm{AD}$ cerebral cortex tissue hemogenates. ${ }^{23}$ In support of this distinction, no increase was found in BuChE immunochemistry associated with histologically normal AD neuropil, where cholinergic neurotransmission occurs. ${ }^{9,21}$

Second, did we scan our AD patients with mild or moderate dementia too early in the course of their disease for incremental plaque-bound $\mathrm{BuChE}$ to be expected? This is unlikely. The mature compact neuritic plaques that are reported to express increased $\mathrm{BuChE}$ activity $^{41}$ and the presynaptic cholinergic deficit are established already even earlier in the course of $\mathrm{AD}$, before the onset of clinical symptoms. ${ }^{42}$

Third, did a mismatched control group obscure BuChE activity gain? The $\mathrm{AD}$ group (mean age, 73 years) was older than the elderly control group (mean age, 62 years), and BuChE activity increased with age in the control subjects (25\% over 32 years). Such a bias would favor underestimating reduction, not gain, in BuChE activity. Accounting for this would equalize the $\mathrm{BuChE}$ and $\mathrm{AChE}$ declines in $\mathrm{AD}$ cerebral cortex to $75 \pm 13 \%$ of normal.

Finally, was the $\left[{ }^{11} \mathrm{C}\right] \mathrm{BMP}$ PET measure flawed? Its rationale is based on the acetylcholine-analog PET method of Irie and colleagues. ${ }^{25}$ This method has been accepted widely as a valid direct measure to quantify in vivo AChE. ${ }^{28,30,43-45}$ Data reported here and previously $^{24,31}$ support the validity of the new $\left[{ }^{11} \mathrm{C}\right] \mathrm{BMP}$ PET measure as a method appropriate to the in vivo assessment of BuChE activity associated with cholinergic terminals. However, tissue heterogeneity on an anatomical scale below PET imaging resolution can complicate quantification of enzyme activity in foci distant from these terminals. For example, even though tissue homogenate assays might measure scarce, but highly concentrated, foci of incremental plaque BuChE that were sparsely perfused, this PET method would underestimate their activity, because delivery of $\left[{ }^{11} \mathrm{C}\right] \mathrm{BMP}$ tracer to the plaque enzyme would be limited. Nevertheless, the $\left[{ }^{11} \mathrm{C}\right] \mathrm{BMP}$ PET method serves well to measure BuChE activity that is associated with 


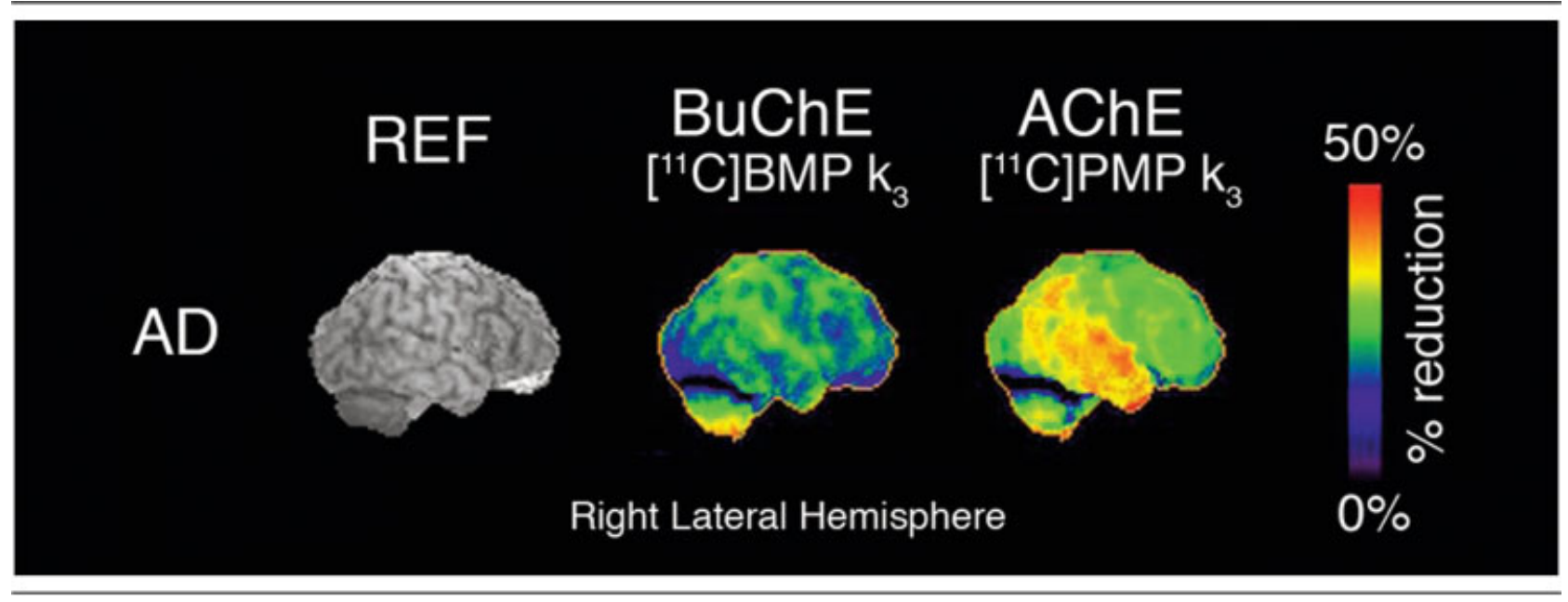

Fig 3. Contrary to in vitro evidence that butyrylcholinesterase (BuChE) is increased substantially in Alzheimer's disease (AD) cerebral cortex, in vivo BuChE activity was not found to be increased. Positron emission tomography scans were performed in elderly control subjects $(n=12)$ and in $A D$ patients $(n=15)$ using $1-\left[{ }^{11} C\right]$ methyl-4-piperidinyl $n$-butyrate $\left(\left[{ }^{11} C\right] B M P\right)$ and $\mathrm{N}-\left[{ }^{11} \mathrm{C}\right]$ methylpiperidin-4-yl propionate ([ $\left.\left.{ }^{11} \mathrm{C}\right] \mathrm{PMP}\right)$ to measure BuChE and acetylcholinesterase (AChE) activities, respectively. In cerebral cortical, striatal, thalamic, and pontocerebellar zones of in vivo AD brain, activity reductions averaged $28 \%$ for AChE and $18 \%$ for BuChE. Image summations are right-left averages of percentage reductions from normal plotted as three-dimensional stereotactic surface projections (reference anatomic map [REF]). Red color represents greater reductions of BuChE or $A C h E$ in $A D$ in comparison with elderly control subjects.

cholinergic terminals, and these are the critical sites where $\mathrm{ACh}$ is concentrated and where cholinesterase inhibition affects cholinergic neurotransmission.

ACh hydrolysis occurs predominantly within cholinergic synapses by outwardly facing, membraneanchored, tetrameric (G4) molecular forms of AChE and BuChE. ${ }^{46}$ Evidence for hydrolysis by BuChE is indirect. First, $\mathrm{BuChE}$ can hydrolyze $\mathrm{ACh}$, but is less efficient than AChE. ${ }^{4}$ Second, inhibition of BuChE in rat brain leads to a dose-dependent increase in $\mathrm{ACh}$ concentration in microdialysate. ${ }^{6}$ Third, complete inhibition of both $\mathrm{AChE}$ and $\mathrm{BuChE}$ is fatal, but AChEnull knock-out mice survive, presumably because $\mathrm{BuChE}$ hydrolyzes $\mathrm{ACh}$ and prevents cholinergic overactivity. ${ }^{40}$ Fourth, when AChE is inhibited in tissue sections, BuChE hydrolyzes the ACh surrogate acetylthiocholine iodide. ' The actual contribution of terminal-associated $\mathrm{BuChE}$ to overall molar hydrolysis rate of ACh in living human cerebral cortex has yet to be quantified. But the incremental BuChE discovered in vitro in $\mathrm{AD}$ cerebral cortex is plaque-bound enzyme in the embryonic G1 molecular form, ${ }^{21}$ not the membrane-anchored G4 BuChE that is considered to play a role in synaptic hydrolysis of ACh. ${ }^{46}$

There is no good evidence that plaque-bound cholinesterases, whether BuChE or AChE, hydrolyze endogenous ACh in the in vivo human brain. In quantitative comparisons, regional losses of cholinergic terminals and AChE activity did not differ throughout the in vivo $\mathrm{AD}$ cerebral cortex. ${ }^{28}$ If in vivo $\mathrm{AChE}$ activity was bolstered strongly by incremental plaque- bound AChE, terminal loss should have been disproportionate to AChE activity loss, but it was not.

Our results suggest that, in $\mathrm{AD}$, the hydrolysis of synaptic ACh by membrane-anchored G4 BuChE declines and is little affected by the buildup of the G1 $\mathrm{BuChE}$ that is found bound to neuritic plaques, neurofibrillary tangles, and vessels affected by congophilic angiopathy. In postmortem $\mathrm{AD}$ cerebral cortex, G4 forms of both $\mathrm{AChE}$ and $\mathrm{BuChE}$ are selectively lost, ${ }^{21,47}$ and G4 AChE is decreased more than is G4 BuChE. ${ }^{21}$ Our in vivo PET data are consistent with those in vitro data.

Consequently, our results did not support the premise that inhibitor therapy should target $\mathrm{BuChE}$ to prevent increased levels of $\mathrm{BuChE}$ from hydrolyzing ACh in AD cerebral cortex. ${ }^{6,7,9}$ In normal brain, only a small amount of $\mathrm{ACh}$ is hydrolyzed by BuChE. Most ACh hydrolysis is catalyzed by AChE, which hydrolyzes ACh much more efficiently than does BuChE. In $\mathrm{AD}$ brain, we found that terminal-associated $\mathrm{BuChE}$ activity was not increased in vivo, rather it was decreased. In addition, we found that no compensatory increase occurred in terminal-associated BuChE activity after months of AChE inhibition therapy. The primacy of AChE inhibition as cholinomimetic therapy in AD is further supported by recent comparative clinical trials that show no difference in efficacy for cognitive improvement between AChE-selective (donepezil) and nonselective (rivastigmine) cholinesterase inhibitors. ${ }^{48,49}$ Yet, current therapeutic drugs provide only about $30 \%$ inhibition of in vivo AChE activity in ce- 
rebral cortex. ${ }^{30,43-45}$ For more efficient reduction of ACh hydrolysis, drug development would be better targeted to increasing $\mathrm{AChE}$ inhibition without serious adverse effects, rather than to increasing BuChE inhibition.

This study was supported by grants from the NIH (National Institute of Neurological Disorders and Stroke, NS 24896, D.E.K., NS15 655, D.E.K.) and the Department of Energy (DE-FG0287ER60561, D.E.K.).

We thank the PET chemistry staff for preparing $\left[{ }^{11} \mathrm{C}\right] \mathrm{BMP}$ and $\left[{ }^{11} \mathrm{C}\right]$ PMP; the technologist staff for data acquisition; J. M. Rothley and L. E. Botti for data workup and analysis; K. A. Wernette and the nurses and staff of the Clinical Core of the Michigan Alzheimer's Disease Research Center for subject recruitment; and N. R. Barbas, N. L. Foster, J. L. Heidebrink, and R. S. Turner for referring their patients.

\section{References}

1. Mesulam MM, Geula C. Overlap between acetylcholinesteraserich and choline acetyltransferse-positive (cholinergic) axons in human cerebral cortex. Brain Res 1992;577:112-120.

2. Wright CI, Geula C, Mesulam MM. Neuroglial cholinesterases in the normal brain and in Alzheimer's disease: relationship to plaques, tangles, and patterns of selective vulnerability. Ann Neurol 1993;34:373-384.

3. Mesulam MM, Geula C. Butyrylcholinesterase activity differentiates the amyloid plaques of aging from those of dementia. Ann Neurol 1994;36:722-727.

4. Silver A. The biology of cholinesterases. Amsterdam: Elsevier, Amsterdam 1974.

5. Weinstock M. Selectivity of cholinesterase inhibition. Clinical implications for the treatment of Alzheimer's disease. CNS Drugs 1999;12:307-323.

6. Giacobini E. Cholinesterase inhibitors: from the Calabar bean to Alzheimer therapy. In: Giacobini E, ed. Cholinesterases and cholinesterase inhibits. London: Martin Dunitz Ltd, 2000: 181-226.

7. Giacobini E, Spiegel R, Enz A, et al. Inhibition of acetyl- and butyryl-cholinesterase in the cerebrospinal fluid of patients with Alzheimer's disease by rivastigmine: correlation with cognitive benefit. J Neurol Transm 2002;109:1053-1065.

8. Ballard CG. Advances in the treatment of Alzheimer's disease: benefits of dual cholinesterase inhibition. Eur Neurol 2002;47: $64-70$.

9. Mesulam MM, Guillozet A, Shaw P, Quinn B. Widely spread butyrylcholinesterase can hydrolyze acetylcholine in the normal and Alzheimer brain. Neurobiol Dis 2002;9:88-93.

10. Darvesh S, Hopkins DA, Geula C. Neurobiology of butyrylcholinesterase. Neurosci Nat Rev 2003;4:131-138.

11. Geula C, Darvesh S. Butyrylcholinesterase, cholinergic neurotransmission and the pathology of Alzheimer's disease. Drugs Today 2004; $40: 711-721$.

12. Davies P, Maloney AJR. Selective loss of central cholinergic neurons in Alzheimer's disease. Lancet 1976;2:1403.

13. Coyle JT, Price DL, De Long MR. Alzheimer's disease: a disorder of cortical cholinergic innervation. Science 1983;219: 1184-1190.

14. Francis PT, Palmer AM, Snape M, Wilcock GK. The cholinergic hypothesis of Alzheimer's disease: a review of progress. J Neurol Neurosurg Psychiatry 1999;66:137-147.

15. Darreh-Shori T, Almkvist O, Guan ZZ, et al. Sustained cholinesterase inhibition in $\mathrm{AD}$ patients receiving rivastigmine for 12 months. Neurology 2002;59:563-572.
16. Liston DR, Nielsen JA, Villalobos A, et al. Pharmacology of selective acetylcholinesterase inhibitors: implications for use in Alzheimer's disease. Eur J Pharmacol 2004;486:9-17.

17. Wilkinson DG, Francis PT, Schwam E, Payne-Parrish J. Cholinesterase inhibitors used in the treatment of Alzheimer's disease. The relationship between pharmacological effects and clinical efficacy. Drugs Aging 2004;21:453-478.

18. Imbimbo BP. Pharmacodynamic-tolerability relationships of cholinesterase inhibitors for Alzheimer's disease. CNS Drugs 2001;15:375-390.

19. Perry EK, Perry RH, Blessed G, Tomlinson BE. Changes in brain cholinesterase in senile dementia of Alzheimer type. Neuropathol Appl Neurobiol 1978;4:273-277.

20. Geula C, Mesulam MM. Special properties of cholinesterases in the cerebral cortex of Alzheimer's disease. Brain Res 1989;498: 185-189.

21. Arendt T, Bruckner MK, Lange M, Bigl V. Changes in acetylcholinesterase and butyrylcholinesterase in Alzheimer's disease resemble embryonic development: a study of molecular forms. Neurochem Int 1992;21:381-396.

22. Gomez-Ramos P, Bouras C, Moran MA. Ultrastructural localization of butyrylcholinesterase on neurofibrillary degeneration sites in the brains of aged and Alzheimer's disease patients. Brain Res 1994;640:17-24.

23. Geula C, Mesulam MM. Cholinesterases and the pathology of Alzheimer disease. Alzheimer Dis Assoc Disord 1995;9:23-28.

24. Snyder SE, Gunupudi N, Sherman PS, et al. Radiolabeled cholinesterase substrates: in vitro methods for determining structure-activity relationships and identification of a positron emission tomography radiopharmaceutical for in vivo measurement of butyrylcholinesterase activity. J Cereb Blood Flow Metab 2001;21:132-143.

25. Irie T, Fukushi K, Akimoto $\mathrm{Y}$, et al. Design and evaluation of radioactive acetylcholine analogs of mapping brain acetylcholinesterase (AChE) in vivo. Nucl Med Biol 1994;21:801-808.

26. Kilbourn MR, Snyder SE, Sherman PS, Kuhl DE. In vivo studies of acetylcholinesterase activity using labeled substrate, $N-\left[{ }^{11} \mathrm{C}\right]$ methylpiperidin-4-yl propionate $\left(\left[{ }^{11} \mathrm{C}\right] \mathrm{PMP}\right)$. Synapse 1996;22:123-131.

27. Snyder SE, Tluczek L, Jewet DM, et al. Synthesis of $1-\left[{ }^{11} \mathrm{C}\right]$ methylpiperidin-4-yl propionate $\left(\left[{ }^{11} \mathrm{C}\right] \mathrm{PMP}\right)$ for in vivo measurements of acetylcholinesterase activity. Nucl Med Biol 1998; 25:751-754.

28. Kuhl DE, Koeppe RA, Minoshima S, et al. In vivo mapping of cerebral acetylcholinesterase activity in aging and Alzheimer's disease. Neurology 1999;52:691-699.

29. Koeppe RA, Frey KA, Snyder SE, et al. Kinetic modeling of $N-\left[{ }^{11} \mathrm{C}\right]$ methylpiperidin-4-yl propionate: alternatives for analysis of an irreversible PET tracer for measurement of acetylcholinesterase activity in human brain. J Cereb Blood Flow Metab 1999;19:1150-1163.

30. Kuhl DE, Minoshima S, Frey KA, et al. Limited donepezil inhibition of acetylcholinesterase measured with positron emission tomography in living Alzheimer cerebral cortex. Ann Neurol 2000;48:391-395.

31. Roivainen A, Rinne J, Virta J, et al. Biodistribution and blood metabolism if $1{ }^{11} \mathrm{C}$-methyl-4-piperidinyl n-butyrate in humans: an imaging agent for in vivo assessment of butyrylcholinesterase activity with PET. J Nucl Med 2004;45:2032-2039.

32. McKhann G, Drachman D, Folstein M, et al. Clinical diagnosis of Alzheimer's disease: report of the NINCDS-ADRDA work group under the auspices of Department of Health and Human Services Task Force on Alzheimer's Disease. Neurology 1984;34:939-944.

33. Hughes CP, Berg L, Danziger WL, et al. A new clinical scale for the staging of dementia. Br J Psychiatry 1982;140:566-572. 
34. Folstein M, Folstein SE, McHugh PR. "Mini Mental State: a practical method for grading the cognitive state of patients for the clinician. J Psychiatr Res 1975;12:189-198.

35. Kilbourn MR, Nguyen TB, Snyder SE, Sherman P. $N-\left[{ }^{11} \mathrm{C}\right]$ methylpiperidine esters as acetylcholinesterase substrates: an in vivo structure-activity study. Nucl Med Biol 1998;25: 755-760.

36. Minoshima S, Frey KA, Koeppe RA, et al. A diagnostic approach in Alzheimer's disease using three-dimensional stereotactic surface projections of $\left[{ }^{18} \mathrm{~F}\right]$ PDG. J Nucl Med 1995;36: $1238-1248$.

37. Giacobini E. Selective inhibitors of butyrylcholinesterase: a valid alternative for therapy of Alzheimer's disease? Drugs Aging 2001;18:891-898.

38. Darvesh S, Walsh R, Kumar R, et al. Inhibition of human cholinesterases by drugs used to treat Alzheimer Disease. Alzheimer Dis Assoc Disord 2003;17:117-126.

39. Atack JR, Perry EK, Bonham JR, et al. Molecular forms of acetylcholinesterase and butyrylcholinesterase in the aged human central nervous system. J Neurochem 1986;47:263-277.

40. Mesulam MM, Guillozet A, Shaw P, et al. Acetylcholinesterase knockouts establish central cholinergic pathways and can use butyrylcholinesterase to hydrolyze acetylcholine. Neuroscience 2002;110:627-639.

41. Guillozet AL, Smiley JF, Mash DC, Mesulam MM. Butyrylcholinesterase in the life cycle of amyloid plaques. Ann Neurol 1997;42:909-918.
42. Beach TG, Kuo YM, Spiegel K, et al. The cholinergic deficit coincides with A-beta deposition at the earliest histopathologic stages of Alzheimer disease. J Neuropathol Exp Neurol 2000; 59:308-313.

43. Kaasinen V, Nagren K, Jarvenpaa T, et al. Regional effects of donepezil and rivastigmine on cortical acetylcholinesterase activity in Alzheimer's disease. J Clin Psychopharmacol 2002;22: 615-620.

44. Shinotoh H, Fukushi K, Nagatsuka S, Irie T. Acetylcholinesterase imaging: its use in therapy evaluation and drug design. Curr Pharm Des 2004;10:1505-1517.

45. Bohnen NI, Kaufer DI, Hendrickson R, et al. Degree of inhibition of cortical acetylcholinesterase activity and cognitive effects by donepezil treatment in Alzheimer's disease. J Neurol Neurosurg Psychiatry 2005;76:315-319.

46. Massoulie J. The origin of the molecular diversity and functional anchoring of cholinesterases. Neurosignals 2002;11:130-143.

47. Atack JR, Perry EK, Bonham JR, et al. Molecular forms of acetylcholinesterase in senile dementia of Alzheimer type: selective loss of intermediate (10S) form. Neurosci Lett 1983;40:199-204.

48. Wilkinson DG, Passmore AP, Bullick R, et al. A multinational, randomised, 12-week, comparative study of donepezil and rivastigmine in patients with mild to moderate Alzheimer's disease. Int J Clin Pract 2002;56:441-446.

49. Lopez-Pousa S, Turon-Estrada A, Garre-Olmo J, et al. Differential efficacy of treatment with acetylcholinesterase inhibitors in patients with mild and moderate Alzheimer's disease over a 6-month period. Dement Geriatr Cogn Disord 2005:19:189-195. 